\title{
Continuous renal replacement therapy in children after cardiac surgery
}

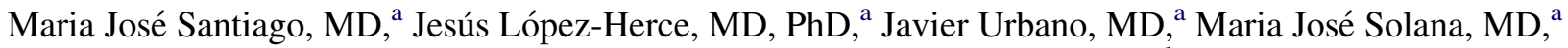 \\ Jimena del Castillo, MD, ${ }^{a}$ Amelia Sánchez, MD, ${ }^{a}$ and Jose María Bellón, $\mathrm{PhD}^{\mathrm{b}}$
}

Objective: The objective was to study the clinical course of children requiring continuous renal replacement therapy (CRRT) after cardiac surgery and to analyze the factors associated with mortality.

\begin{abstract}
Methods: A prospective observational study was performed that included all children requiring CRRT after cardiac surgery, comparing these patients with other critically ill children requiring CRRT. Univariate and multivariate analyses were performed to determine the influence of each factor on mortality.

Results: Eighty-one (4.9\%) of 1650 children undergoing cardiac surgery required CRRT; 65 of them (80.2\%) presented multiorgan failure. Children starting CRRT after cardiac surgery had lower mean arterial pressure and lower urea and creatinine levels, and were more likely to require mechanical ventilation than other children on CRRT. The incidence of complications was similar. Cardiac surgery increased the probability of requiring CRRT for more than 14 days. Mortality was $43 \%$ in children receiving CRRT after cardiac surgery and $29 \%$ in other children $(P=.05)$. Factors associated with mortality in the univariate analysis were age less than 12 months, weight less than $10 \mathrm{~kg}$, higher Pediatric Risk of Mortality Score, hypotension, lower urea and creatinine on starting CRRT, and use of hemofiltration. In the multivariate analysis, the only factor associated with mortality was hypotension on starting CRRT (hazard ratio, 4.01; 95\% confidence interval, 1.2-13.4; $P=.024)$.
\end{abstract}

Conclusions: Although only a small percentage of children undergoing cardiac surgery required CRRT, mortality in these patients was high. Hypotension at the time of starting the technique was the only factor associated with a higher mortality. (J Thorac Cardiovasc Surg 2013;146:448-54)

Advances in the surgical treatment of children with congenital heart disease have led to an increase in survival. However, children undergoing complex cardiac surgery and those in whom multiorgan failure develops present a higher incidence of acute kidney injury (AKI). ${ }^{1}$ Patients postcardiac surgery are prone to develop AKI because of low cardiac output, hemolysis, and septic complications. ${ }^{2}$ The incidence of AKI after cardiac surgery in adults was estimated at $2.7 \%$ to $30 \%$, depending on the definition used, ${ }^{3-6}$ and the presence of AKI was associated with a significant increase in mortality. ${ }^{6}$ Approximately $1 \%$ to $6.8 \%$ of adult patients require dialysis after cardiac surgery,

From the Pediatric Intensive Care Department, ${ }^{a}$ Hospital General Universitario Gregorio Marañón, Madrid, Spain; and Biomedical Research Foundation of the Hospital General Universitario Gregorio Marañón, ${ }^{b}$ Madrid, Spain.

This study has been financed in part by Project No. RD08/0072: Mother and Child Health and Development Network of the Carlos III Institute, Madrid, Spain.

Disclosures: Authors have nothing to disclose with regard to commercial support.

Received for publication May 10, 2010; revisions received Nov 4, 2010; accepted for publication Feb 14, 2013.

Address for reprints: Jesús López-Herce, MD, PhD, Servicio de Cuidados Intensivos Pediátricos, Hospital General Universitario Gregorio Marañón, Dr Castelo 47, 28009 Madrid, Spain (E-mail: pielvi@hotmail.com).

$0022-5223 / \$ 36.00$

Copyright $(92013$ Published by Elsevier Inc. on behalf of The American Association for Thoracic Surgery

http://dx.doi.org/10.1016/j.jtcvs.2013.02.042 and the need for dialysis is associated with a high mortality, a more complicated in-hospital course, and a higher risk of infectious complications. ${ }^{5,6}$

In children, the reported incidence of AKI requiring renal replacement therapy after cardiac surgery with cardiopulmonary bypass varies from $1 \%$ to $17 \%$, depending on the complexity of the surgery. ${ }^{2,7-10}$ Continuous renal replacement therapy (CRRT) offers continuous, steady fluid removal and uremic toxin clearance. The intensity of treatment can be titrated to treat or prevent volume overload. Myocardial depressant factors can be removed, myocardial performance can be improved, and nutrition can be optimized. ${ }^{3}$

There is little information on the clinical course of children requiring CRRT after cardiac surgery, ${ }^{2}$ and there are no studies that have determined the factors associated with survival. The objective of the present study was to analyze the clinical course of children on CRRT after cardiac surgery and the factors associated with survival.

\section{PATIENTS AND METHODS}

A prospective, observational study was performed that included all critically ill children who were admitted to the pediatric intensive care unit (PICU) between January 1, 1996, and June 1, 2009, and treated with CRRT. ${ }^{11}$ The study was approved by the local institutional review board. 


\section{Abbreviations and Acronyms \\ ACT = activated clotting time \\ AKI = acute kidney injury \\ $\mathrm{CI}=$ confidence interval \\ CRRT = continuous renal replacement therapy \\ HR = hazard ratio \\ PELOD $=$ Pediatric Logistic Organ Dysfunction \\ PICU = pediatric intensive care unit \\ PIM $=$ Pediatric Index of Mortality \\ PRISM $=$ Pediatric Risk of Mortality Score}

This secondary study has analyzed the subgroup of children undergoing cardiac surgery. During the study period, CRRT was required by 174 critically ill children. A total of 81 patients with CRRT ( 55 boys [68\%] and 26 girls [32\%], with a mean [standard deviation] age of 50 [64] months) were in the postoperative period of cardiac surgery, and these were the patients included in the study. There were 43 patients $(53 \%)$ aged less than 1 year, and $26 \%$ of patients weighed less than $5 \mathrm{~kg}$. Three different CRRT monitors were used to perform treatment: BSM321C, Prisma, and Prismaflex (Hospal, Madrid, Spain). Catheters between $5 \mathrm{~F}$ and $11 \mathrm{~F}$ were used depending on the age and weight of the child.

Polyacrylonitrile AN69 or polysulfone hollow-fiber hemofilters were used depending on the patient's body surface area and the pump used. $\mathrm{M} 10^{\mathrm{R}}$ (Hospal, Lyon, France) $0.04 \mathrm{~m}^{2}$ or $\mathrm{FH} 22^{\mathrm{R}}$ (Renaflow; Minntech, Minneapolis, Minn) $0.15 \mathrm{~m}^{2}$ filters were used in children weighing less than $5 \mathrm{~kg}$; M60 ${ }^{\mathrm{R}}$ (Hospal, Lyon, France) $0.6 \mathrm{~m}^{2}$ or HF400 ${ }^{\mathrm{R}}$ (LinC Medical Systems, Leicestershire, UK) $0.3 \mathrm{~m}^{2}$ filters (Renaflow) were used in patients weighing 5 to $35 \mathrm{~kg}$; and M100 ${ }^{\mathrm{R}}$ (Hospal, Lyon, France) $0.9 \mathrm{~m}^{2}$ filters were used in children weighing more than $35 \mathrm{~kg}$.

Commercially prepared, bicarbonate-buffered hemofiltration replacement fluid (Clearflex; Bieffe Medital, Madrid, Spain) was infused prefilter. Bicarbonate-buffered dialysis fluid (Dialisan CVVHD; Hospal, Madrid, Spain) was used in patients on continuous venovenous hemodiafiltration.

The intensivist decided when to initiate CRRT regardless of the time of day, if there was anuria or oliguria $(<0.5 \mathrm{~mL} / \mathrm{kg} / \mathrm{h})$, and especially when the fluid balance was positive with high doses of diuretics (eg, furosemide 1 $\mathrm{mg} / \mathrm{kg} / \mathrm{h}$ ) for 6 to 12 hours.

Continuous venovenous hemofiltration was used in $30 \%$ of patients, and continuous venovenous hemodiafiltration was used in $70 \%$ of patients; the decision on whether to use hemofiltration or hemodiafiltration was the responsibility of the treating physician and was based on the patient's need for solute clearance.

A heparin bolus of 20 to $50 \mathrm{IU} / \mathrm{kg}$ was administered at the time of starting CRRT; the dose was determined according to the baseline activated clotting time (ACT): Patients with a normal baseline ACT received a bolus of $50 \mathrm{IU} / \mathrm{kg}$, which was reduced to $20 \mathrm{IU} / \mathrm{kg}$ in patients with a baseline ACT more than 200 seconds. This was followed by a continuous heparin infusion via the pre-blood pump port, aiming to maintain a postfilter ACT between 150 and 200 seconds.

A prospective record of the following data was created for all patients at the time of starting CRRT: age, weight, sex, diagnosis, severity scores (Pediatric Index of Mortality [PIM] II, ${ }^{12}$ Pediatric Risk of Mortality Score [PRISM] II, ${ }^{13}$ and Pediatric Logistic Organ Dysfunction $[\text { PELOD }]^{14}$ ), number of organs affected according to the International Pediatric Sepsis Consensus Conference, ${ }^{15}$ blood pressure, vasoactive drug requirements, doses of dopamine and adrenaline, vasoactive inotropic score, ${ }^{16}$ lactic acid levels, $\mathrm{pH}$ and base excess, creatinine, urea, alanine aminotransferase, bilirubin, and type of CRRT monitor used. Hypotension was defined as a mean arterial pressure more than 2 standard deviations below normal for the patient's age. Cardiac output was not measured in most of the patients. Low cardiac output was defined by clinical criteria (poor peripheral perfusion, blood pressure, heart rate) plus echocardiography and analytic methods (venous oxygen saturation, lactic acid). During therapy, a daily record was kept of the use of hemodiafiltration or hemofiltration, maximum dose of heparin, ultrafiltration rate, life of each filter, CRRT-related complications, and mortality during admission to the PICU.

Statistical analysis was performed using SPSS version 15.0 (SPSS Inc, Chicago, Ill). The chi-square, Fisher exact, and Mann-Whitney tests were used to compare the qualitative and quantitative variables. Univariate and multivariate Cox regression analyses were performed to analyze the influence of each factor on mortality. In the multivariate model, we included the baseline factors that were associated with mortality by univariate regression analysis.

\section{RESULTS}

A total of 1650 patients in the postoperative period of cardiac surgery were admitted to the unit between January 1996 and April 2009, 94 of whom (5.6\%) received heart transplants. CRRT was required in 81 patients $(4.9 \%)$, including 18 who had undergone heart transplantation $(19 \%)$. The most common diagnoses and operations performed and the risk adjustment for surgery for congenital heart disease ${ }^{17}$ are listed in Table 1 . Thirteen patients received extracorporeal membrane oxygenation assistance. The most common indications for CRRT were AKI with hypervolemia $(37 \%)$, isolated AKI $(36 \%)$, and hypervolemia refractory to diuretic treatment $(25 \%)$. The characteristics of the CRRT are summarized in Table 2. Venous access was most commonly achieved by cannulation of the femoral vein. In 13 patients, the pump was inserted into the extracorporeal membrane oxygenation circuit. ${ }^{18}$

The characteristics of the patients, their clinical severity, and the treatment they were receiving at the time of starting CRRT are detailed in Table 3, which also shows a comparison of the characteristics with the other children treated by CRRT. After cardiac surgery, patients were more likely to require CRRT than other patients $(4.9 \%$ vs $1.6 \%)$. Of the children requiring CRRT after cardiac surgery, $38 \%$ were aged less than 6 months. There was no difference in age in comparison with other patients on CRRT, although a larger percentage of patients in the post-cardiac surgery group were aged less than 12 months $(53 \%$ vs $35 \%$; $P=.02)$. Forty-seven children $(58 \%)$ weighed less than $10 \mathrm{~kg}$, and 15 children (26\%) weighed less than $5 \mathrm{~kg}$. There were no differences in the mortality calculated according to the PRISM, PIM, or PELOD scores in children on CRRT after cardiac surgery and in other patients on CRRT. Organ failure of more than 3 organs was detected in $80.2 \%$ of patients requiring CRRT after cardiac surgery.

The mean arterial pressure in children with heart disease was significantly lower than in the other patients, and $95 \%$ required vasoactive drugs, with a higher inotropic index than the other patients. In addition, more of these patients were on mechanical ventilation at the time of starting CRRT. The mean urea and creatinine levels at the time of 
TABLE 1. Surgical procedures in the patients with heart disease

\begin{tabular}{lrr}
\hline \multicolumn{1}{c}{ Surgical procedure } & No. & $\%$ \\
\hline Heart transplant & 18 & 22.2 \\
Surgical repair of ventricular septal defect & 5 & 6.2 \\
Surgical repair of complete atrioventricular canal defect & 6 & 7.4 \\
Repair of tetralogy of Fallot & 10 & 12.3 \\
Norwood's reconstruction & 2 & 2.5 \\
Bidirectional Glenn procedure & 9 & 11.1 \\
Fontan procedure & 12 & 14.8 \\
Critical aortic stenosis; Ross-Konno operation & 2 & 2.5 \\
Aortic arch reconstruction & 2 & 2.5 \\
Mitral valvuloplasty & 7 & 8.6 \\
Transposition of the great arteries; arterial switch operation & 5 & 6.2 \\
Pulmonary atresia with major aortopulmonary collateral & 3 & 3.7 \\
arteries; unifocalization surgery & & \\
RACHS classification & & \\
RACHS 2 & 24 & 38.1 \\
RACHS 3 & 32 & 50.8 \\
RACHS 4 & 3 & 4.8 \\
RACHS 5 & 2 & 3.1 \\
RACHS 6 & 2 & 3.1 \\
\hline
\end{tabular}

RACHS, Risk Adjustment for Congenital Heart Surgery.

starting therapy were lower. The mean duration of the filters was 50 hours, which was significantly longer than in the other patients, although the maximum dose of heparin was slightly higher (Table 3 ).

Complications developed in $65 \%$ of the children on CRRT after cardiac surgery. The incidence of complications and a comparison with the other patients are shown in Table 4. Hypokalemia was the only complication with a significantly higher incidence in patients on CRRT after cardiac surgery than in other patients.

Continuation of CRRT for more than 14 days was required by 22 patients $(27 \%)$ after cardiac surgery and for more than 21 days by 15 patients $(18.5 \%)$. In the logistic regression study, the diagnosis of heart disease increased the probability of requiring prolonged CRRT (hazard ratio [HR], 1.491; 95\% confidence interval [CI], 1.299-2.840; $P=.001)$.

Table 5 compares the characteristics of the patients aged less than 1 year postcardiac surgery who required CRRT with the characteristics of the older patients. Initial urea and creatinine, and duration of filters and hemodiafiltration were lower and hypophosphatemia was higher in patients aged less than 12 months. Mortality of younger patients was higher, but the difference was not statistically significant.

The mortality of patients undergoing cardiac surgery who required CRRT was higher than that of patients who did not need require CRRT ( $43 \%$ vs $4 \% ; P<.001$ ). Mortality also was higher in children postcardiac surgery than in the other patients who required CRRT ( $43 \%$ vs $29 \% ; P=.051$ ). The cause of death was multiorgan failure in $46 \%$ of patients, cardiogenic shock in $40 \%$ of patients, brain death in $3 \%$
TABLE 2. Characteristics of continuous renal replacement therapy in children who underwent cardiac surgery

\begin{tabular}{|c|c|}
\hline Characteristic & No. $(\%)$ \\
\hline \multicolumn{2}{|l|}{ Vascular access } \\
\hline Femoral vein & $54(67 \%)$ \\
\hline Jugular vein & $13(16 \%)$ \\
\hline Subclavian vein & $6(7 \%)$ \\
\hline Inserted into the ECMO circuit & $3(4 \%)$ \\
\hline Other access & $5(6 \%)$ \\
\hline \multicolumn{2}{|l|}{ Type of CRRT pump } \\
\hline Prisma (Hospal, Madrid, Spain) & $63(77 \%)$ \\
\hline BSM321C (Hospal) & $15(19 \%)$ \\
\hline Prismaflex (Hospal) & $3(4 \%)$ \\
\hline \multicolumn{2}{|l|}{ Catheter } \\
\hline $5 \mathrm{~F}$ & $8(10 \%)$ \\
\hline $6.5 \mathrm{~F}$ & $42(52 \%)$ \\
\hline $7-9 \mathrm{~F}$ & $13(16 \%)$ \\
\hline $10-11 \mathrm{~F}$ & $10(12 \%)$ \\
\hline Various & $5(6 \%)$ \\
\hline \multicolumn{2}{|l|}{ Filter surface area } \\
\hline $0.04 \mathrm{~m}^{2}$ & $25(31 \%)$ \\
\hline $0.15 \mathrm{~m}^{2}$ & $7(8 \%)$ \\
\hline $0.6 \mathrm{~m}^{2}$ & $28(35 \%)$ \\
\hline $0.9 \mathrm{~m}^{2}$ & $13(16 \%)$ \\
\hline Various & $8(10 \%)$ \\
\hline \multicolumn{2}{|l|}{ Technique } \\
\hline Hemofiltration & $24(30 \%)$ \\
\hline Hemodiafiltration & $57(70 \%)$ \\
\hline Flow rates & Mean \\
\hline Blood flow (mL/kg/min) & 5.5 \\
\hline Replacement fluid flow (mL/h) & 289 \\
\hline Dialysis fluid flow $(\mathrm{mL} / \mathrm{h})$ & 464 \\
\hline Total effluent flow $(\mathrm{mL} / \mathrm{kg} / \mathrm{h})$ & 53 \\
\hline Total duration of treatment (h) & 271 \\
\hline No. of filters/patient & 6 \\
\hline Mean filter life (h) & 50 \\
\hline
\end{tabular}

$\overline{E C M O \text {, Extracorporeal membrane oxygenation; } C R R T \text {, continuous renal replacement }}$ therapy.

of patients, and withdrawal of life-sustaining care due to irreversibility of the underlying disease in $11.4 \%$ of patients.

Table 6 shows the univariate analysis of the risk factors for mortality in children on CRRT after cardiac surgery. The factors associated with an increase in the risk of mortality were age less than 12 months, weight less than $10 \mathrm{~kg}$, the presence of hypotension before starting CRRT, the state of clinical severity measured by the PRIMS at the time of starting CRRT, and lower urea and creatinine concentrations at the time of starting CRRT (Table 6).

The mean age of the patients who died was lower (30 months) than that of the survivors (64 months) $(P=.026)$. Patients who died had a higher PRISM score (18 vs 14 ; $P=.007)$ and PELOD score (21 vs $17 ; P=.046)$. The mortality in children with hypotension before starting CRRT was significantly higher than in other children on CRRT after cardiac surgery $(51.1 \%$ vs $25.8 \% ; P=.03)$. 
TABLE 3. Comparison between children after cardiac surgery and other critically ill patients requiring continuous renal replacement therapy

\begin{tabular}{|c|c|c|c|}
\hline & $\begin{array}{c}\text { Cardiac surgery } \\
\qquad \begin{array}{c}\mathbf{n}=\mathbf{8 1} \\
\text { Mean (SD) }\end{array}\end{array}$ & $\begin{array}{c}\text { Other patients } \\
\mathbf{n}=\mathbf{9 3} \\
\text { Mean (SD) }\end{array}$ & $P$ \\
\hline Age (mo) & $50(64)$ & $55(64)$ & .807 \\
\hline PRISM (\%M) & $21(22)$ & $20(25)$ & .172 \\
\hline PIM (\%M) & $9(14)$ & $12(17)$ & .363 \\
\hline PELOD (\%M) & $20(29)$ & $25(28)$ & .168 \\
\hline No. of organ failures & $3.1(0.7)$ & $2.9(1.5)$ & .213 \\
\hline Lactate $(\mathrm{mmol} / \mathrm{L})$ & $3.1(3.6)$ & $3.1(3.7)$ & .440 \\
\hline Arterial $\mathrm{pH}$ & $7.35(0.1)$ & $7.29(0.1)$ & .065 \\
\hline MAP (mm Hg) & $55(14)$ & $66(23)$ & .003 \\
\hline Vasoactive inotropic score & $75.6(141.9)$ & $55.1(90.1)$ & $<.001$ \\
\hline $\begin{array}{l}\text { Dose of epinephrine } \\
\qquad(\mu \mathrm{g} / \mathrm{kg} / \mathrm{min})\end{array}$ & $0.6(1.5)$ & $0.4(0.8)$ & .008 \\
\hline $\begin{array}{l}\text { Dose of dopamine } \\
(\mu \mathrm{g} / \mathrm{kg} / \mathrm{min})\end{array}$ & $10(6)$ & $8(7)$ & .003 \\
\hline Initial creatinine $(\mathrm{mg} / \mathrm{dL})$ & $1.1(0.8)$ & $1.9(1.7)$ & .002 \\
\hline Initial urea (mg/dL) & $70(46)$ & $98(68)$ & .004 \\
\hline ALT (IU/L) & $223(764)$ & $181(642)$ & .635 \\
\hline Bilirubin (mg/dL) & $2.1(2.8)$ & $1.6(1.4)$ & .609 \\
\hline $\begin{array}{l}\text { Maximum dose of heparin } \\
(\mathrm{U} / \mathrm{kg} / \mathrm{h})\end{array}$ & $17(11)$ & $13(10)$ & .042 \\
\hline $\begin{array}{l}\text { Total effluent flow rate } \\
(\mathrm{mL} / \mathrm{kg} / \mathrm{h})\end{array}$ & $53(19)$ & $62(33)$ & .518 \\
\hline Mean filter life (h) & $50(48)$ & $36(31)$ & .027 \\
\hline Total duration of therapy & $\begin{array}{c}271(357) \\
\text { Patients, n (\%) }\end{array}$ & $\begin{array}{c}148(188) \\
\text { Patients, n (\%) }\end{array}$ & .025 \\
\hline Sex (male) & $55(68 \%)$ & $50(54 \%)$ & .06 \\
\hline Mechanical ventilation & $78(98 \%)$ & $67(73 \%)$ & $<.001$ \\
\hline $\begin{array}{l}\text { Dialysis technique } \\
\text { (hemodiafiltration) }\end{array}$ & $57(70 \%)$ & $72(77 \%)$ & .290 \\
\hline Vasoactive drugs & $77(95 \%)$ & $59(63 \%)$ & $<.001$ \\
\hline Initial hypotension & $45(59 \%)$ & $27(34 \%)$ & .001 \\
\hline
\end{tabular}

Patients treated using hemodiafiltration had a lower mortality than those treated using only hemofiltration. There were no differences in the filtration rate (dialysis + ultrafiltration) between the survivors $(35[22] \mathrm{mL} / \mathrm{kg} / \mathrm{h}$ ) and the patients who died $(36[21] \mathrm{mL} / \mathrm{kg} / \mathrm{h})$, or in the decrease in urea and creatinine levels. The only factor associated with mortality in the multivariate analysis was hypotension before starting CRRT (HR, 4.01; 95\% CI, 1.2-13.4; $P=.024$ ).

\section{DISCUSSION}

Renal replacement therapy used in children with AKI after cardiac surgery has varied over time. Initially, the most widely used technique was peritoneal dialysis, but in recent decades this has been displaced by venovenous CRRT
TABLE 4. Complications of continuous renal replacement therapy: Comparison between children with heart disease and other patients

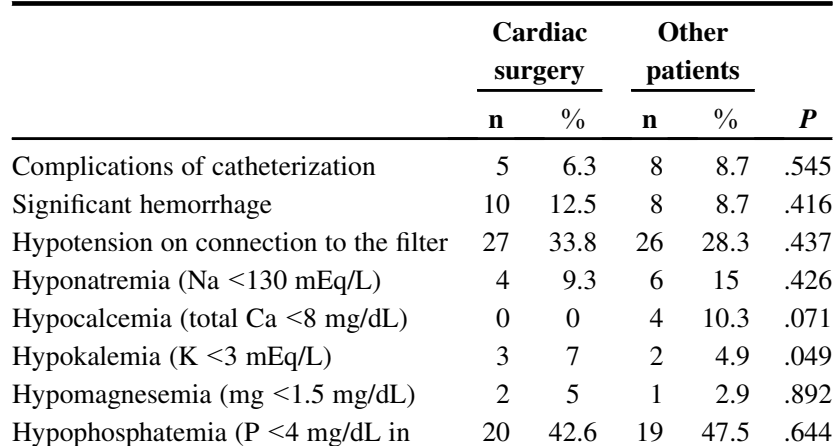

children aged $<6$ y and $\mathrm{P}<3 \mathrm{mg} / \mathrm{dL}$

in children aged $>6 \mathrm{y}$ )

\begin{tabular}{llllll} 
Thrombocytopenia & 13 & 27.7 & 11 & 23.4 & .636 \\
\hline
\end{tabular}

$\mathrm{Na}$, Sodium; $\mathrm{Ca}$, calcium; $K$, potassium; $P$, phosphorus. Definitions: Complications of catheterization: hemorrhage with a decrease of $>2 \mathrm{~g} / \mathrm{dL}$ in the hemoglobin concentration or hypotension or the need for transfusion or withdrawal of the catheter from that site, thrombosis, pneumothorax, and altered limb perfusion. Significant hemorrhage: a decrease of $>2 \mathrm{~g} / \mathrm{dL}$ in the hemoglobin concentration in the first 24 hours after bleeding or hypotension and that required packed red cell transfusion. Hypotension on connection to the filter: During the first 60 minutes after the connection to CRRT: a decrease in mean arterial pressure $>20 \mathrm{~mm} \mathrm{Hg}$ over baseline or $>2$ standard deviations below the normal value for age and that required volume expansion or an increase in the dose of vasoactive drugs that the patient was receiving. Thrombocytopenia: platelets $<100,000 / \mathrm{mm}^{3}$.

(except in the neonatal period) because of the greater efficacy and predictability of this latter technique. However, there is only 1 study $^{19}$ that has compared the 2 techniques, and few patients were analyzed in each group (5). In the study by Fleming and colleagues, ${ }^{19}$ CRRT achieved a better fluid and electrolyte balance than peritoneal dialysis, although there was no difference in survival. In our study, $81(4.9 \%)$ of the 1650 patients who underwent open surgery required CRRT. This figure is similar to the figures reported by other authors. ${ }^{3-5,20}$

It is important to define the AKI, hypervolemia, and criteria to start CRRT, which is difficult because the indication depends not only on the renal function but also on the hypervolemia, fluid balance, and failure of other organs. Although it is not possible to define the precise indications, the most important fact is that creatinine and urea levels are not the definitive criteria.

The time of the CRRT initiation also is important. The time between the clinical indication of CRRT and the beginning of the technique is most important. ${ }^{21}$ Several studies have shown that one of the most important prognosis factors is the positive fluid balance before initiation of CRRT. ${ }^{22,23} \mathrm{It}$ is important to begin CRRT early if the fluid balance is positive with increasing doses of diuretics.

In some PICUs, the initiation of CRRT is delayed because the nephrologist team determines when to start the technique, normally in the morning. In our PICU, the intensivist determines when to start the technique regardless of the time of day, and there is little delay before the indication 
TABLE 5. Comparison of children requiring continuous renal replacement therapy after cardiac surgery in relation to age

\begin{tabular}{|c|c|c|c|}
\hline & $\begin{array}{c}<1 \mathrm{y} \\
\mathrm{n}=\mathbf{4 3} \\
\text { Mean (SD) }\end{array}$ & $\begin{array}{c}>1 \text { y } \\
\mathbf{n}=\mathbf{3 8} \\
\text { Mean (SD) }\end{array}$ & $\boldsymbol{P}$ \\
\hline PRISM (\%M) & $21.3(20.5)$ & $19.9(23.4)$ & .342 \\
\hline PIM (\%M) & $9.9(17.1)$ & $8.9(9.9)$ & .600 \\
\hline PELOD $(\% \mathrm{M})$ & $22.6(27.6)$ & $27.2(28.5)$ & .470 \\
\hline No. of organ failures & $3.1(0.7)$ & $3.1(0.7)$ & .747 \\
\hline Lactate $(\mathrm{mmol} / \mathrm{L})$ & $2.5(2.4)$ & $3.7(4.6)$ & .388 \\
\hline Arterial pH & $7.34(0.07)$ & $7.37(0.08)$ & .532 \\
\hline MAP (mm Hg) & $52.3(13.7)$ & $58.7(14.7)$ & .008 \\
\hline Vasoactive-inotropic score & $88.8(189.4)$ & $61(53.1)$ & .620 \\
\hline $\begin{array}{l}\text { Dose of epinephrine } \\
(\mu \mathrm{g} / \mathrm{kg} / \mathrm{min})\end{array}$ & $0.7(1.9)$ & $0.5(0.6)$ & .563 \\
\hline Dose of dopamine $(\mu \mathrm{g} / \mathrm{kg} / \mathrm{min})$ & $11.7(6.8)$ & $9(4.1)$ & .086 \\
\hline Initial creatinine $(\mathrm{mg} / \mathrm{dL})$ & $0.7(0.5)$ & $1.5(0.8)$ & $<.001$ \\
\hline Initial urea $(\mathrm{mg} / \mathrm{dL})$ & $53(30.3)$ & $87.6(52.9)$ & .000 \\
\hline ALT (IU/L) & $52(100)$ & $408(1093)$ & .276 \\
\hline Bilirubin (mg/dL) & $1.2(1.3)$ & $3.1(3.7)$ & .037 \\
\hline $\begin{array}{l}\text { Maximum dose of heparin } \\
(\mathrm{U} / \mathrm{kg} / \mathrm{h})\end{array}$ & $16.3(12.5)$ & $18.1(10)$ & .274 \\
\hline $\begin{array}{l}\text { Total effluent flow rate } \\
(\mathrm{mL} / \mathrm{kg} / \mathrm{h})\end{array}$ & $61.2(20.2)$ & $48.3(16.9)$ & .025 \\
\hline Mean filter life (h) & $38.7(43.8)$ & $63.1(49.1)$ & .001 \\
\hline Total duration of therapy (h) & $\begin{array}{l}228(348) \\
\text { Patients, n (\%) }\end{array}$ & $\begin{array}{c}319(365) \\
\text { Patients, n (\%) }\end{array}$ & .003 \\
\hline Sex (male) & $12(27.9 \%)$ & $24(63.2 \%)$ & .390 \\
\hline Mechanical ventilation & $43(100 \%)$ & $14(36.8 \%)$ & .123 \\
\hline $\begin{array}{l}\text { Dialysis technique } \\
\text { (hemodiafiltration) }\end{array}$ & $24(55.8 \%)$ & $33(86.8 \%)$ & .002 \\
\hline Vasoactive drugs & $40(93 \%)$ & $37(97.4 \%)$ & .368 \\
\hline Mortality & $22(51.3 \%)$ & $13(34.2 \%)$ & .177 \\
\hline Initial hypotension & $19(48.7 \%)$ & $26(70.3 \%)$ & .056 \\
\hline $\begin{array}{r}\text { Complications of } \\
\text { catheterization }\end{array}$ & $4(9.3 \%)$ & $1(2.7 \%)$ & .224 \\
\hline Significant hemorrhage & $6(14 \%)$ & $4(10.8 \%)$ & .672 \\
\hline $\begin{array}{l}\text { Hypotension on connection } \\
\text { to the filter }\end{array}$ & $14(32.6 \%)$ & $13(35.1 \%)$ & .808 \\
\hline $\begin{array}{l}\text { Hyponatremia } \\
\qquad(\mathrm{Na}<130 \mathrm{mEq} / \mathrm{L})\end{array}$ & $3(17.6 \%)$ & $1(3.8 \%)$ & .128 \\
\hline $\begin{array}{l}\text { Hypocalcemia (total } \mathrm{Ca}<8 \\
\mathrm{mg} / \mathrm{dL} \text { ) }\end{array}$ & $0(0 \%)$ & $0(0 \%)$ & 一 \\
\hline Hypokalemia $(\mathrm{K}<3 \mathrm{mEq} / \mathrm{L})$ & $1(5.9 \%)$ & $0(0 \%)$ & .945 \\
\hline $\begin{array}{l}\text { Hypomagnesemia } \\
\qquad(\mathrm{mg}<1.5 \mathrm{mg} / \mathrm{dL})\end{array}$ & $1(6.3 \%)$ & $1(4.2 \%)$ & .686 \\
\hline $\begin{array}{l}\text { Hypophosphatemia } \\
\qquad(\mathrm{P}<4 \mathrm{mg} / \mathrm{dL} \text { in children } \\
\text { aged }<6 \text { y and } \mathrm{P}<3 \mathrm{mg} / \mathrm{dL} \\
\text { in children aged }>6 \mathrm{y})\end{array}$ & $14(70 \%)$ & $6(22.2 \%)$ & .001 \\
\hline $\begin{array}{r}\text { Thrombocytopenia } \\
\left(<100.000 / \mathrm{mm}^{3}\right)\end{array}$ & $14(63.6 \%)$ & $12(48 \%)$ & .282 \\
\hline
\end{tabular}

$S D$, Standard deviation; PRISM, Pediatric Risk of Mortality; $\% M$, mortality; PIM, Pediatric Index of Mortality; PELOD, Pediatric Logistic Organ Dysfunction; MAP, mean arterial pressure; $A L T$, alanine aminotransferase; $N a$, sodium; $K$, potassium; $P$, phosphorus. Vasoactive-inotropic score $(\mu \mathrm{g} / \mathrm{kg} / \mathrm{min})$ : dopamine + dobutamine + $($ epinephrine $\times 100)+($ norepinephrine $\times 100)+($ isoproterenol $\times 100)+$ (milrinone $\times 15$ ).
TABLE 6. Univariate Cox regression analysis of factors associated with mortality in children on continuous renal replacement therapy after cardiac surgery

\begin{tabular}{lrlr}
\hline & HR* & \multicolumn{1}{c}{ 95\% CI } & \multicolumn{1}{c}{$\boldsymbol{P}$} \\
\hline Age $\leq 12$ mo & 1.99 & $(1-3.98)$ & .050 \\
Weight $<10 \mathrm{~kg}$ & 2.31 & $(1.13-4.74)$ & .022 \\
PRISM $\geq 21$ & 2.18 & $(0.99-4.80)$ & .052 \\
PIM & 1.40 & $(0.73-2.72)$ & .314 \\
PIM \%M & 1.00 & $(0.98-1.03)$ & .747 \\
PELOD $\geq 22$ & 1.73 & $(0.64-4.70)$ & .278 \\
No. of organ failures & 0.89 & $(0.54-1.48)$ & .651 \\
Lactate & 0.99 & $(0.9-1.09)$ & .832 \\
Initial arterial pH & 0.37 & $(0-183)$ & .817 \\
Mean arterial pressure & 2.04 & $(0.99-4.18)$ & .052 \\
Hypotension & 2.25 & $(1-5.08)$ & .050 \\
Vasoactive drugs & 0.57 & $(0.13-2.4)$ & .441 \\
Dose of adrenaline & 1.49 & $(1.19-1.88)$ & .001 \\
Dose of dopamine & 1.05 & $(0.98-1.12)$ & .160 \\
Mechanical ventilation & 20.90 & $(0-38)$ & .680 \\
Initial creatinine & 0.46 & $(0.25-0.85)$ & .013 \\
Initial urea & 0.99 & $(0.98-1)$ & .040 \\
Creatinine at the end of CRRT & 0.75 & $(0.3-1.91)$ & .552 \\
Urea at the end of CRRT & 1.01 & $(0.99-1.02)$ & .311 \\
Alanine aminotransferase & 1.00 & $(1-1)$ & .894 \\
Bilirubin (mg/dL) & 0.94 & $(0.7-1.24)$ & .646 \\
Filtration technique (hemofiltration) & 8.36 & $(3.25-21.5)$ & $<.001$ \\
Ultrafiltration rate & 0.99 & $(0.98-1.01)$ & .526 \\
Total effluent flow & 1.02 & $(1-1.04)$ & .073 \\
Filter surface $<0.15$ m ${ }^{2}$ & 1.54 & $(0.72-3.3)$ & .262 \\
Initial period of the study 1996-2002 & 1.32 & $(0.61-2.86)$ & .484 \\
\hline HR, & &
\end{tabular}

$\overline{H R}$, Hazard ratio; $C I$, confidence interval; PRISM, Pediatric Risk of Mortality; PIM, Pediatric Index of Mortality; $\% M$, mortality; PELOD, Pediatric Logistic Organ Dysfunction; $C R R T$, continuous renal replacement therapy. *HR $>1$ indicates higher mortality.

and initiation of the technique; thus, many of our patients had normal levels of creatinine and urea levels at the beginning of the CRRT.

A large proportion of children who required CRRT after cardiac surgery were aged less than 12 months, and 26\% weighed less than $5 \mathrm{~kg}$. This makes it more difficult to perform CRRT because of the complexity of canalization, the smaller caliber of the vascular access and catheters used, and the greater hemodynamic repercussion of the technique because the extracorporeal circuit represents a larger percentage of body volume.

Although more patients in the period after cardiac surgery had hypotension, and a larger percentage required inotropic drugs or mechanical ventilation at the time of starting CRRT, the indices of severity (PRISM, PIM, and PELOD) were not significantly higher.

Low cardiac output is the main factor related to AKI after cardiac surgery. In those undergoing heart transplantation, the toxicity of immunosuppression drugs also contributes to AKI, which could explain the high frequency of CRRT in these patients. 
The mean urea and creatinine at the time of starting CRRT was lower in patients undergoing cardiac surgery, probably because renal replacement therapy was started earlier in this group of patients if hypervolemia refractory to diuretics was detected.

CRRT was continued for approximately twice as long in children after cardiac surgery than in other critically ill children, likely reflecting a slower recovery of the underlying disease in patients with low cardiac output syndrome. In the logistic regression study, cardiac surgery significantly increased the risk of prolonged CRRT.

Mean filter life was slightly longer in the patients on CRRT after cardiac surgery, although the heparin doses were slightly higher in these patients, which could explain the moderate increase in filter life.

There was a high incidence of CRRT-related complications, similar to the incidence reported by other authors. ${ }^{2,23,24}$ However, the majority of complications were mild (eg, electrolyte imbalance) and corrected during treatment. We did not find a higher percentage of complications in children after cardiac surgery than in other critically ill children, except for a slightly higher frequency of hypokalemia.

Mortality in children after cardiac surgery $(43 \%)$ was higher than in other critically ill children (29\%). Few studies have analyzed the mortality of patients requiring CRRT after cardiac surgery. The onset of dialysisdependent acute renal failure increased mortality. In adults, mortality in this group is $30 \%$ to $70 \% .^{20,25,26}$ Factors associated with a higher mortality in adults requiring CRRT after cardiac surgery are poor left ventricular function, diabetes mellitus, peripheral vascular disease, the need for emergency surgery, and preoperative serum creatinine levels. ${ }^{20-23}$

Only 1 study $^{2}$ has performed a retrospective analysis of the clinical course of 25 children on CRRT after cardiac surgery. In the study by Jander and colleagues, ${ }^{2} 32 \%$ of the patients died during CRRT, although the final mortality was of $76 \%$.

Few studies have analyzed prognostic factors in critically ill children in whom renal failure develops or who require CRRT. Clinical severity, hemodynamic disturbances, number of organ failures, and a positive fluid balance before starting treatment are the main factors that determine the prognosis. . $2,23,27,28$

In our study of children after cardiac surgery, those aged more than 1 year and weighing more than $10 \mathrm{~kg}$ had a lower mortality than younger or smaller patients, as has been reported in other studies in children. ${ }^{23,29}$ However, in the multivariate logistic regression, age was not a factor that significantly increased the risk of mortality.

Patients treated with only hemofiltration (ie, those who presented hypervolemia with no marked increase in the urea or creatinine) presented a higher mortality than patients treated with hemodiafiltration, in whom the urea and creatinine levels were higher. This finding also was observed by Jander and colleagues. ${ }^{2}$ The mode of CRRT probably did not affect the outcome; however, it will be necessary to perform prospective studies in children to analyze this aspect. On the other hand, although there is no evidence for the superiority of hemofiltration or dialysis, the use of both convective and diffusive clearance enables a low filtration fraction to be maintained.

Some studies found that the use of high volumes of ultrafiltration improved the prognosis in critically ill adult patients undergoing renal replacement therapy, ${ }^{30}$ although more recent studies have not confirmed these findings. ${ }^{31}$ In our study, we used high mean filtration rates and did not observe differences in the ultrafiltration rate between patients who died and patients who survived.

In the multivariate analysis, the only risk factor that was related to a higher risk of mortality was a previous hemodynamic disturbance, evidenced as hypotension (HR, 4.01; $95 \% \mathrm{CI}, 1.2-13.4 ; P=.024)$, a finding also reported in other studies in children. ${ }^{8,18}$ This supports the idea that the outcome in children requiring dialysis is not directly related to the CRRT but rather to the previous state of clinical severity and, particularly in patients after cardiac surgery, to hemodynamic disturbances.

The PRISM, PIM, and PELOD scores were significantly higher in the patients who died than in the survivors, agreeing with the results of other studies. ${ }^{11,32}$ However, the 3 scales underestimated the risk of mortality. Other studies also have indicated that the PRISM has a poor ability to predict mortality in patients with acute renal failure s3,34 $^{33}$ and patients on intermittent dialysis.

\section{CONCLUSIONS}

Although only a small percentage of children undergoing cardiac surgery require CRRT, there is an elevated mortality in these patients, higher than in other critically ill children requiring CRRT. Hypotension at the time of starting the treatment is the only factor associated with a higher mortality.

The authors thank the nurses and doctors of the Pediatric Intensive Care Department of the Gregorio Marañón General University Hospital for their collaboration in performing this study.

\section{References}

1. Goldstein SL, Somers MJ, Baum MA, Symons JM, Brophy PD, Blowey D, et al Pediatric patients with multi-organ dysfunction syndrome receiving continuous renal replacement therapy. Kidney Int. 2005;67:653-8.

2. Jander A, Tkaczyk M, Pagowska-Klimek I, Pietrzykowski W, Moll J, Krajewski W, et al. Continuous veno-venous hemodiafiltration in children after cardiac surgery. Eur J Cardiothorac Surg. 2007;31:1022-8.

3. Bent P, Tan HK, Bellomo R, Buckmaster J, Doolan L, Hart G, et al. Early and intensive continuous hemofiltration for severe renal failure after cardiac surgery. Ann Thorac Surg. 2001;71:832-7. 
4. Bapat V, Sabetai M, Roxburgh J, Young C, Venn G. Early and intensive continuous veno-venous hemofiltration for acute renal failure after cardiac surgery. Interact Cardiovasc Thorac Surg. 2004;3:426-30.

5. Ostermann ME, Taube D, Morgan CJ, Evans TW. Acute renal failure following cardiopulmonary bypass: a changing picture. Intensive Care Med. 2000;26: 565-71.

6. Chertow GM, Levy EM, Hammermeister KE, Grover F, Daley J. Independent association between acute renal failure and mortality following cardiac surgery. Am J Med. 1998;104:343-8.

7. Pedersen KR, Povlsen JV, Christensen S, Pedersen J, Hjortholm K, Larsen SH, et al. Risk factors for acute renal failure requiring dialysis after surgery for congenital heart disease in children. Acta Anaesthesiol Scand. 2007;51:1344-9.

8. Boigner H, Brannath W, Hermon M, Stoll E, Burda G, Trittenwein G, et al. Predictors of mortality at initiation of peritoneal dialysis in children after cardiac surgery. Ann Thorac Surg. 2004;77:61-5.

9. Goldstein SL. Overview of pediatric renal replacement therapy in acute renal failure. Artif Organs. 2003;27:781-5.

10. Bunchman TE, McBryde KD, Mottes TE, Gardner JJ, Maxvold NJ, Brophy PD. Pediatric acute renal failure: outcome by modality and disease. Pediatr Nephrol. 2001;16:1067-71.

11. Santiago MJ, Lopez-Herce J, Urbano J, Solana MJ, del Castillo J, Ballestero Y, et al. Clinical course and mortality risk factors in critically ill children requiring continuous renal replacement therapy. Intensive Care Med. 2010;36:843-9.

12. Shann F, Pearson G, Slater A, Wilkinson K. Pediatric index of mortality (PIM). A mortality prediction model for children in intensive care. Intensive Care Med. 1997;23:201-7.

13. Pollack MM, Ruttimann UE, Getson PR. The pediatric risk of mortality (PRISM) score. Crit Care Med. 1988;16:1110-6.

14. Leteurtre S, Martinot A, Duhamel A, Gauvin F, Grandbastien B, Nam TV, et al. Development of a pediatric multiple organ dysfunction score: use of two strategies. Med Decis Making. 1999;19:399-410.

15. Goldstein B, Giroir B, Randolph A. International pediatric sepsis consensus conference: definitions for sepsis and organ dysfunction in pediatrics. Pediatr Crit Care Med. 2005;6:2-8.

16. Gales MG, Gurney JG, Yen AH, Napoli ML, Gajarski RJ, Ohye RG, et al. Vasoactive-inotropic score as a predictor of morbidity and mortality in infants after cardiopulmonary bypass. Pediatr Crit Care Med. 2010;11:234-8.

17. Jenkins KJ, Gauvreau K, Newburger JW, Spray TL, Moller JH, Iezzoni LI. Consensus-based method for risk adjustment for surgery for congenital heart disease. J Thorac Cardiovasc Surg. 2002;123:110-8.

18. Santiago MJ, Sanchez A, Lopez-Herce J, Perez R, del Castillo J, Urbano J, et al. The use of continuous renal replacement therapy in series with extracorporeal membrane oxygenation. Kidney Int. 2009;76:1289-92.

19. Fleming F, Bohn D, Edwards H, Cox P, Geary D, McCrindle BW, et al. Renal replacement therapy after repair of congenital heart disease in children. A comparison of hemofiltration and peritoneal dialysis. J Thorac Cardiovasc Surg. 1995;109:322-31.

20. Rosner MH, Portilla D, Okusa MD. Cardiac surgery as a cause of acute kidney injury: pathogenesis and potential therapies. J Intensive Care Med. 2008;23:3-18.

21. Elahi M, Asopa S, Pflueger A, Hakim N, Matata B. Acute kidney injury following cardiac surgery: impact of early versus late haemofiltration on morbidity and mortality. Eur J Cardiothorac Surg. 2009;35:854-63.

22. Foland JA, Fortenberry JD, Warshaw BL, Pettignano R, Merritt RK, Heard ML, et al. Fluid overload before continuous hemofiltration and survival in critically ill children: a retrospective analysis. Crit Care Med. 2004;32:1771-6.

23. Symons JM, Chua AN, Somers MJ, Baum MA, Bunchman TE, Benfield MR, et al. Demographic characteristics of pediatric continuous renal replacement therapy: a report of the prospective pediatric continuous renal replacement therapy registry. Clin J Am Soc Nephrol. 2007;2:732-8.

24. Finkel KW, Podoll AS. Complications of continuous renal replacement therapy. Semin Dial. 2009;22:155-9.

25. Vidal S, Richebé P, Barandon L, Calderon J, Tafer N, Pouquet O, et al. Evaluation of continuous veno-venous hemofiltration for the treatment of cardiogenic shock in conjunction with acute renal failure after cardiac surgery. Eur J Cardiothorac Surg. 2009;36:572-9.

26. Elahi MM, Lim MY, Joseph RN, Dhannapuneni RR, Spyt TJ. Early hemofiltration improves survival in post-cardiotomy patients with acute renal failure. Eur J Cardiothorac Surg. 2004;26:1027-31.

27. Ball EF, Kara T. Epidemiology and outcome of acute kidney injury in New Zealand children. J Paediatr Child Health. 2008;44:642-6.

28. Bresolin N, Silva C, Halllal A, Toporovski J, Fernandes V, Goes J, et al. Prognosis for children with acute kidney injury in the intensive care unit. Pediatr Nephrol. 2009;24:537-44.

29. Ponikvar R, Kandus A, Urbancic A, Kornhauser AG, Primozic J, Ponikvar JB. Continuous renal replacement therapy and plasma exchange in newborns and infants. Artif Organs. 2002;26:163-8.

30. Ronco C, Bellomo R, Homel P, Brendolan A, Dan M, Piccinni P, et al. Effects of different doses in continuous veno-venous haemofiltration on outcomes of acute renal failure: a prospective randomised trial. Lancet. 2000;356:26-30.

31. Palevsky PM, Zhang JH, O'Connor TZ, Chertow GM, Crowley ST, Choudhury D, et al. Intensity of renal support in critically ill patients with acute kidney injury. N Engl J Med. 2008;359:7-20.

32. Zobel G, Kuttnig M, Ring E, Grubbauer HM. Clinical scoring systems in children with continuous extracorporeal renal support. Child Nephrol Urol. 1990; 10:14-7.

33. Martin C, Saran R, Leavey S, Swartz R. Predicting the outcome of renal replacement therapy in severe acute renal failure. ASAIO J. 2002;48:640-4.

34. Medina A, López-Herce J, López Y, Antón M, Concha A, Rey C, et al. Insuficiencia renal aguda en niños criticamente enfermos. Estudio preliminar. An Pediatr (Barc). 2004;61:509-14 